\title{
Taxonomical Study of Chrysosplenium L. (Saxifragaceae) in Korea Based on Chemical Composition
}

\author{
Hyun-Jun Kim, Hea-Seok Jeong ${ }^{1}$ and Shin-Ho Kang ${ }^{1}$ * \\ Division of Plant Conservation, Korea National Arboretum of the Korea Forest Service, Pocheon 487-821, Korea \\ ${ }^{1}$ Department of Natural Medicine Resources, Semyung University, Jecheon 390-711, Korea
}

\begin{abstract}
Components extracted from 7 species and 18 populations of Chrysosplenium in Korea were compared and analyzed using GC-MS analysis. 57 components ( $\geq 80 \%$ quality) were identified, of which neophytadiene, palmitic acid and phytol were found at all the taxa. Percentage composition of isolated extracts showed a clear difference in components type and GC-MS profile. On the basis of that result, data matrix was made and cluster analysis using UPGMA was conducted. From the result of cluster analysis, two groups were recombined; one with alternate leaves comprised $C$. japonicum in Ser. Alternifolia and C. flagelliferum in Ser. Flagellifera and the other with opposite leaves gradationally comprised C. psuedofauriei in Ser. Sinica, C. ramosum in Ser. Oppositifolia and C. sphaerospermum, C. valdepilosum, C. flaviflorum in Ser. Pilosa. These chemotaxonomic results agreed in general with those of existing studies on external morphology and molecular. In conclusion, chemical composition can be an useful characters in understanding the relation analysis among interspecific and intraspecific complex with the help of cluster analysis of 7 species and 18 populations of Chrysosplenium in Korea.
\end{abstract}

Key words - Saxifragaceae, Chrysosplenium, Chemotaxonomy, GC-MS, UPGMA

\section{Introduction}

About 57 65 species of Chrysosplenium L. in Saxifragaceae have been known to be distributed throughout the world (Hara, 1957; Pan, 2001). This genus except for 2 species distributed in South America is restrictively distributed at the northern hemisphere; 2 species in Northeastern America, 4 species in Northwestern America, 2 species in Europe and most of the remaining taxa in eastern Asia (35 species in China, 18 species in Japan) (Spongberg, 1972; Pan, 2001; Iwatsuki et al., 2001). This genus was established as taxon by Linne (1753) for the frist time, classified as 2 subgenus (Gamosplenium, Dialyspelium), according to arrangement type of sepals by Maximowicz (1877) and divided as 2 sections (Gamosplenium, Dialyspelium), according to arrangement type of leaves by Franchet (1890). On the other hand, Hara (1957) reclassified this genus 17 series, maintaining that the classification of Franchet wasn't nature classification. As the studies on Chrysosplenium L. in Korea, Forbes and Hemsley (1887) reported for the first time,

*Corresponding author. E-mail : idec5974@semyung.ac.kr and then Palibin (1898), Nakai (1909), Chung (1937, 1965), Park (1949, 1974), Lee (1976), Lee (1996a), Lee (1996b) reported in the plant checklist and illustrated book of flora. Additionally, Chung and Kim (1988) recorded this genus as 7 species and 1 variety, and $\mathrm{Kim}$ (2007) as 5 species and 3 varieties C. flagelliferum F. Shmidt, C. alternifolium var. sibiricum Seringe ex DC., C. japonicum (Maxim.) Makino, C. ramosum Maxim., C. pseudofauriei H. Lév., C. flaviflorum Ohwi, C. pilosum var. fulvum (Terracc.) Hara, C. pilosum var. valdepilosum Ohwi. Recently, Han et al. (2011) raised C. pilosum var. fulvum and C. pilosum var. valdepilosum to the status of species, C. sphaerospermum and C. valdepilosum, on the basis of taxonomic treatments such as ITS sequences and seed characteristics of C. pilosum complex faced with the different taxonomic views. As the studies on the chemical compounds of Chrysosplenium, 77 components comprising Eicoane, Palmitic Acid ethyl ester, Dibutyl phthate, (z,z,z)-9,12,15-Octadecatrienoic acid, ethyl ester, 2,6-Butylated hydroxytoluene and 5,6,7,7a-Tetrahydro 4,4,7a-trimethyl-2 (4H)-benzofuranone were identified and isolated in C. nudicaule (Yang et al., 2004), and 4 components chrysosplenol B, chrysosplenol D, chrysosplenoside B and 
chrysosplenoside D in C. alternifolium (Gudej and Czapski, 2009). As chemotaxonomic studies, Bohm and Collins (1979) reported that the arrangement of leaves was divided into alternate and opposite according to the containing degree of O-methylated flavones and supported the opinion of Franchet (1890) that Chrysosplenium should be classied into 2 sections, Oppositifolia and Alternifolia. But, studies on the components composition of Chrysosplenium in Korea are difficult to find and chemotaxonomic studies aren't carried out until now.

So, this study was conducted to determine the chemical components of Chrysosplenium in Korea and the interspecific chemical differences of it, and compare our findings with those of morphological and phylogenetic classification.

\section{Materials and Methods}

\section{Plant Samples}

18 populations representing $C$. sphaerospermum, $C$. valdepilosum, C. flaviflorum, C. psuedofauriei, C. ramosum, C. japonicum and C. flagelliferum were sampled in Korea from April to May, 2011. Information of taxa and sources used in this experiment was as Table 1. Voucher specimens were dried an kept at Herbarium of Semyung University (NMR).

\section{Extraction and purification}

The whole plants of collected samples were used as specimens for extraction after washing with distilled water, air-drying under shade for a week and then grinding. $200 \mathrm{mg}$ of grinded specimens dissolved in $5 \mathrm{~mL}$ of $99.9 \% \mathrm{MeOH}$ was extracted 3 times for 1 hour with the use of ultrasonic extraction. $\mathrm{MeOH}$ extracts from ultrasonic extraction were filtered with $0.45 \mu \mathrm{m}$ nylon syringe filter and then used in GC-MS analysis.

\section{GC-MS analysis}

GC-MS analysis for the compositions of extracts was performed using same GC/MSD (HP6890GC/5973MSD, USA), equipped with Ultra 2 (Agilent 19091B-102, 315Max). The injection volume was $2 \mu \mathrm{L}$. The carrier gas used was helium, at a constant flow rate of $0.4 \mathrm{~mL} / \mathrm{min}$. The oven temperature was initially held at $120^{\circ} \mathrm{C}$ for 5 minutes, then

Table 1. Collected materials used in this study

\begin{tabular}{|c|c|c|}
\hline Taxa & Abbrev. & Source and voucher \\
\hline C. sphaerospermum Maxim. 1 & CSPH1 & GB: Mt. Palgong, Gunwi-gun / NMR: H. J. Kim11041601 \\
\hline C. sphaerospermum Maxim. 2 & $\mathrm{CSPH} 2$ & GW: Mt. Chiak, Wonju-si / NMR: H. J. Kim11051801 \\
\hline C. sphaerospermum Maxim. 3 & CSPH3 & JN: Isl. Naro, Goheung-gun / NMR: H. J. Kim11043001 \\
\hline C. sphaerospermum Maxim. 4 & CSPH4 & JJ: Mt. Jeolmul, Jeju-si / NMR: H. J. Kim11051701 \\
\hline C. sphaerospermum Maxim. 5 & CSPH5 & JJ: Mt. Barime, Jeju-si / NMR: H. J. Kim11051702 \\
\hline C. valdepilosum (Ohwi) S.H. Kang \& J.W. Han 1 & CVAL1 & GG: Mt. Bukbae, Gapyeoung-gun / NMR: H. J. Kim11050401 \\
\hline C. valdepilosum (Ohwi) S.H. Kang \& J.W. Han 2 & CVAL2 & GW: Mt. Baekun, Wonju-si / NMR: H. J. Kim11050601 \\
\hline C. valdepilosum (Ohwi) S.H. Kang \& J.W. Han 3 & CVAL3 & GW: Mt. Taebaek, Taebaek-si / NMR: H. J. Kim11052101 \\
\hline C. flaviflorum Ohwi 1 & CFLV1 & GB: Mt. Cheongyang, Bonghwa-gun / NMR: H. J. Kim11041701 \\
\hline C. flaviflorum Ohwi 2 & CFLV2 & GG: Mt. Myeongji, Gapyeoung-gun / NMR: H. J. Kim11050401 \\
\hline C. flaviflorum Ohwi 3 & CFLV3 & CB: Mt. Samdobong, Yeongdong-gun / NMR: H. J. Kim110513 \\
\hline C. pseudofauriei H.Lév 1 & CPSE1 & GW: Mt. Taebaek, Taebaek-si / NMR: H. J. Kim110521002 \\
\hline C. pseudofauriei H.Lév 2 & CPSE2 & GB: Mt. Yongmum, Yechon-gun / NMR: H. J. Kim11051102 \\
\hline C. ramosum Maxim. & CRAM1 & GW: Mt. Taebaek, Taebaek-si / NMR: H. J. Kim11052103 \\
\hline C. japonicum (Maxim.) Makino 1 & CJAP1 & CB: Baegun-myeon, Jecheon-si / NMR: H. J. Kim11050101 \\
\hline C. japonicum (Maxim.) Makino 2 & CJAP2 & GB: Mt. Palgong, Gunwi-gun / NMR: H. J. Kim11041602 \\
\hline C. flagelliferum F.Shmidt 1 & CFLG1 & GG: Mt. Cheonma, Namyangju-si / NMR: H. J. Kim11050501 \\
\hline C. flagelliferum F.Shmidt 2 & CFLG2 & GW: Mt. Taebaek, Taebaek-si / NMR: H. J. Kim11052104 \\
\hline
\end{tabular}

CB: Chungcheongbuk-do, GB: Gyeongsangbuk-do, GG: Gyeonggi-do, GW: Gangwon-do, JN: Jeollanam-do, JJ: Jeju-do. 
raised to $300^{\circ} \mathrm{C}, 5^{\circ} \mathrm{C} / \mathrm{min}$. Components of the extracts were identified with the aid of the database (Wiley7N).

\section{Cluster analysis}

The phenogram was prepared using 7 species comprising 18 populations in Chrysosplenium in Korea. Every analyzed components ( $\geq 80 \%$ quality) were treated as OTU (Operational Taxonomic Unit) and each OTU marked as value of "1", when founded, or " 0 ", when not founded. After the above procedure, data matrix was prepared. The phenogram was prepared using average linkage cluster analysis according to average distance. UPGMA (unweighted pair group method with arithmetic average) of PAUP 4.02b (Swoffrd, 1998) was used for statistical analysis.

\section{Results and Discussion}

\section{Components composition}

On the basis of results from this study of 7 species comprising 18 populations in Chrysosplenium in Korea using GC-MS analysis, 57 components ( $\geq 80 \%$ quality) were identified as Table 2. Percentage composition of extracts identified from Chrysosplenium in Korea was listed in Table 3.

There was some difference among 7 taxa in components composition; 21 Kinds of components in C. sphaerospermum, 15 in C. valdepilosum, 19 in C. flaviflorum, 22 in C. psuedofauriei, 14 in C. ramosum, 24 in C. japonicum, 21 in C. flagelliferum were identified. Number of components specie in each taxa was 6 (compound $8,12,15,18,21,57$ ) in C. sphaerospermum, 1 (compound 33) in C. valdepilosum, 6 (compound 5, 10, 19, $36,41,43$ ) in C. flaviflorum, 5 (compound 1, 6, 22, 40, 47) in C. psuedofauriei, 1 (compound 30 ) in C. ramosum, 5 (compound 7, 11, 38, 48, 49) in C. japonicum and 3 (compound $4,34,42)$ in C. flagelliferum. Neophytadiene (0.93 11.08\%), Palmitic acid (0.63 3.34\%), Phytol (0.97 9.45\%) were detected in all the taxa experimented. There was a definite difference in components types and GC-MS profile among the taxa.

In addition, it was showed that $C$. japonicum population from Mt. Palgong contained 20 kinds of components, the most, and C. sphaerospermum population from Isl. Naro 6 kinds, the least. In the meanwhile, it was judged that geographical variation of C. sphaerospermum. C. flaviflorum occurred to some extent in chemical components composition of them. The chemical composition of C. sphaerospermum populations from Isl. Jeju and Isl. Naro was generally similar to that from the inland areas, but, compound 2, 8, 12, 18, 21, 23, 45, 56 identified from the interior population weren't identified in C. sphaerospermum populations from island areas and compound 3, 29, 53, 57 were specific in populations from Isl. Jeju and Isl. Naro. Collected populations of $C$. sphaerospermum were usually distributed at the margins of moist valleys. Light condition of their habitats was good because the flowering season, early spring, of them didn't overlap with the actual growing period of other plants. Above chemical composition difference might be an indication of local differnetiation between inland populations and island populations rather than different environmental conditions of their habitats. In C. flaviflorum, compound 13, 14, 20, 25, 26, 39 were identified in populations from Mt. Myeongji, Mt. Cheongyang and Mt. Samdobong but compound 36, 37, 53 were specific in population from Mt. Samdobong. Populations from Mt. Myeongji and Mt. Cheongyang were usually distributed at an altitude of about 100 200 m and populations from Mt. Samdobong were restricted to highland over $1,000 \mathrm{~m}$. Water condition was judged to be similar in that all the populations of $C$. flaviflorum were distributed at the margins of moist valleys. Light condition of their habitats was also similar because their flowering season, early spring, didn't overlap with the actual growing period of other plants. So, it was estimated that these components differences might be caused by those of altitude of their habitats.

From this study, differences of components among taxa and populations were identified. These differences were assumed to be caused by those of geographical or inhabiting environments. So, it was suggested that additional studies on environmental characteristics, morphological variations and genetic diversity according to their natural habitats should be conducted.

\section{Cluster analysis}

For conducting cluster analysis, data matrix was made on the basis of components composition of 7 species and 18 populations in Chrysosplenium cluster analysis was carried out using UPGMA of data matrix drawn and phenogram was accomplished (Fig. 1.). 
Table 2. The list of identified componunds

\begin{tabular}{|c|c|c|c|}
\hline No. & Compound name & No. & Compound name \\
\hline 1 & 8-Aminoquinoline & 31 & Rotenalone \\
\hline 2 & 4,7,7-Trimethylbicyclo[3.3.0]octan-2-one & 32 & $\begin{array}{l}\text { 4,4,6a,8a,11,12,14b-Heptamethyl-1,2,3,4,4a,5,6,6a,7,8,8a,9,1 } \\
\text { 0,11,12,12a,13,14,14a,14b-eicosahydropicen-3-ol }\end{array}$ \\
\hline 3 & 5-Oxymethylfurfurole & 33 & Bicyclo[2.2.1]heptane, 2-chloro-2,7,7-trimethyl-, exo- \\
\hline 4 & 4-Vinylguaiacol & 34 & 3-Eicosene, (E)- \\
\hline 5 & Chloroquinone & 35 & 11,14,17-Eicosatrienoic acid, methyl ester \\
\hline 6 & Leucoglucosan & 36 & 9-Octadecenamide, (Z)- \\
\hline 7 & 4-Methyl-2,6-di-tert-butylphenol & 37 & (E)-5,10-secocholest-1(10)-en-3,5-dione \\
\hline 8 & Butylated Hydroxytoluene & 38 & 2-Methyl-7-nonadecene \\
\hline 9 & 2-Ethylquinoline & 39 & 1-Octadecene \\
\hline 10 & 3-Deoxy-d-mannoic lactone & 40 & 1-Nonadecene \\
\hline 11 & 4-Propylfuro[3,2-c]pyridine & 41 & 13-Tertadecen-1-ol acetate \\
\hline 12 & Megastigmatrienone & 42 & 1-Docosene \\
\hline 13 & Tetradecanoic acid & 43 & 1-Heptadecene \\
\hline 14 & Neophytadiene & 44 & Campesterol \\
\hline 15 & 1,4-Eicosadiene & 45 & 23S-Methylcholesterol \\
\hline 16 & 9,12-Octadecadienoic acid (Z,Z)-, methyl ester & 46 & Hexadecanoic acid, 2-hydroxy-1-(hydroxymethyl) ethyl ester \\
\hline 17 & Methyl palmitate & 47 & Docosanoic acid, methyl ester \\
\hline 18 & Pentadecanoic acid, 14-methyl-, methyl ester & 48 & a-Glyceryl linoleate \\
\hline 19 & (E)-3-Tetradecen-5-yne & 49 & B-Monolinolein \\
\hline 20 & Palmitic acid & 50 & $\begin{array}{l}\text { Nonanoic acid, 9-(3-hexenylidenecyclopropylidene)-, 2-hydroxy- } \\
\text { 1-(hydroxymethyl)ethyl ester, (Z,Z,Z)- }\end{array}$ \\
\hline 21 & Hexadecanoic acid, trimethylsilyl ester & 51 & Stigmasterol, 22,23-dihydro- \\
\hline 22 & 8,11-Octadecadienoic acid, methyl ester & 52 & $\begin{array}{l}\text { 1,5-Dimethyl-6-(1,5-dimethylhexyl)-15,16-epoxy-18-oxatetr } \\
\text { acyclo[9.6.1.0(2,10).0(5,9)]octdecane-13-one }\end{array}$ \\
\hline 23 & $9,12,15$-Octadecatrienoic acid, methyl ester & 53 & (23S)-ethylcholest-5-en-3ß-ol \\
\hline 24 & 9,12-Octadecadienoic acid, methyl ester & 54 & $\gamma$-Sitosterol \\
\hline 25 & Linolenic acid methyl ester & 55 & $\begin{array}{l}2,6,10,14,18,22 \text {-Tetracosahexaene, } 2,6,10,15,19,23 \text {-hexamethyl-, } \\
\text { (all-E)- }\end{array}$ \\
\hline 26 & Phytol & 56 & 4,9,13,17-Tetramethyl-4,8,12,16-octadecatetraenal \\
\hline 27 & Linoleic acid & 57 & $2,6,10,14,18$-Pentamethyl-2,6,10,14,18-eicosapentaene \\
\hline 28 & Ethyl linoleolate & & \\
\hline 29 & 9,12,15-Octadecatrien-1-ol, (Z,Z,Z)- & & \\
\hline 30 & 4-Hexadecen-6-yne, (E)- & & \\
\hline
\end{tabular}

Chrysosplenium in Korea comprises 5 series; Alternifolia, Flagellifera, Oppositifolia, Sinica, Pilosa. Ser. Alternifolia and Ser. Flagellifera have alternate leaves, and Ser. Oppositifolia, Ser. Sinica and Ser. Pilosa have opposite leaves (Hara, 1957; Chung and Kim, 1988). From this study, Chrysosplenium in Korea was divided into two groups on the basis of components analysis using GC-MS. That was agreed to system of morphological classification and view of Bohm and Collins (1979) that the arrangements of leaves were divided into alternate and opposite according to the containing degree of O-methylated flavones.

C. japonicum in Ser. Alternifolia and C. flagelliferum in Ser. 
Korean J. Plant Res. 26(6) : 718 725 (2013)

Table 3. Percentage composition of extracts identified from Chrysosplenium in Korea

\begin{tabular}{|c|c|c|c|c|c|c|c|c|c|c|c|c|c|c|c|c|c|c|c|c|c|}
\hline \multirow{2}{*}{ Taxa } & \multicolumn{21}{|c|}{ Compound } \\
\hline & 1 & 2 & 3 & 4 & 5 & 6 & 7 & 8 & 9 & 10 & 11 & 12 & 13 & 14 & 15 & 16 & 17 & 18 & 19 & 20 & 21 \\
\hline CSPH1 & - & - & - & - & - & - & - & 0.48 & - & - & - & 0.39 & - & 4.52 & 0.72 & 0.74 & - & 0.66 & - & 0.95 & 0.75 \\
\hline CSPH2 & - & 0.46 & - & - & - & - & - & - & - & - & - & - & 0.82 & 3.66 & 0.61 & 0.30 & - & - & - & 1.69 & 0.47 \\
\hline CSPH3 & - & - & - & - & - & - & - & - & - & - & - & - & - & 4.86 & - & 0.31 & - & - & - & 0.89 & - \\
\hline CSPH4 & - & - & 5.98 & - & - & - & - & - & - & - & - & - & 7.73 & 1.61 & 0.33 & - & - & - & - & 1.05 & - \\
\hline CSPH5 & - & - & 1.79 & - & - & - & - & - & - & - & - & - & - & 3.17 & 0.44 & - & - & - & - & 0.63 & - \\
\hline CVAL1 & - & - & - & - & - & - & - & - & - & - & - & - & 14.42 & 11.08 & - & - & - & - & - & 0.92 & - \\
\hline CVAL2 & - & - & 2.15 & - & - & - & - & - & - & - & - & - & 9.29 & 7.31 & - & - & - & - & - & 0.78 & - \\
\hline CVAL3 & - & - & - & - & - & - & - & - & - & - & - & - & 1.04 & 8.12 & - & - & 0.34 & - & - & 1.01 & - \\
\hline CFLV1 & - & - & - & - & - & - & - & - & - & 1.13 & - & - & 8.13 & 3.25 & - & - & - & - & 0.60 & 1.47 & - \\
\hline CFLV2 & - & - & 1.77 & - & 1.65 & - & - & - & - & - & - & - & 9.13 & 2.48 & - & - & - & - & - & 1.81 & - \\
\hline CFLV3 & - & - & 1.72 & - & 1.14 & - & - & - & - & - & - & - & 11.37 & 8.96 & - & - & - & - & - & 0.80 & - \\
\hline CPSE1 & - & - & - & - & - & 7.75 & - & - & 1.50 & - & - & - & 0.50 & 2.65 & - & - & 0.56 & - & - & 1.01 & - \\
\hline CPSE2 & 0.20 & - & - & - & - & 3.05 & - & - & - & - & - & - & 0.20 & 1.04 & - & - & 0.30 & - & - & 0.68 & - \\
\hline CRAM1 & - & - & - & - & - & - & - & - & 1.21 & - & - & - & - & 2.97 & - & - & 0.53 & - & - & 1.94 & - \\
\hline CJAP1 & - & - & - & - & - & - & - & - & - & - & - & - & 1.54 & 0.93 & - & - & 0.40 & - & - & 3.34 & - \\
\hline CJAP2 & - & - & - & - & - & - & 0.48 & - & - & - & 0.49 & - & 1.03 & 1.83 & - & 0.55 & 0.62 & - & - & 2.57 & - \\
\hline CFLG1 & - & - & - & 0.27 & - & - & - & - & - & - & - & - & 0.95 & 3.67 & - & - & 0.38 & - & - & 2.70 & - \\
\hline CFLG2 & - & 0.24 & - & 0.62 & - & - & - & - & - & - & - & - & 0.65 & 2.26 & - & - & 0.30 & - & - & 0.81 & - \\
\hline
\end{tabular}

Table 3. Continued

\begin{tabular}{|c|c|c|c|c|c|c|c|c|c|c|c|c|c|c|c|c|c|c|c|c|c|}
\hline \multirow{2}{*}{ Taxa } & \multicolumn{21}{|c|}{ Compound } \\
\hline & 22 & 23 & 24 & 25 & 26 & 27 & 28 & 29 & 30 & 31 & 32 & 33 & 34 & 35 & 36 & 37 & 38 & 39 & 40 & 41 & 42 \\
\hline CSPH1 & - & 0.28 & - & - & 7.69 & 0.75 & - & - & - & - & 2.57 & - & - & - & - & - & - & - & - & - & - \\
\hline CSPH2 & - & 0.93 & - & - & 2.36 & 0.65 & - & - & - & - & 10.08 & - & - & - & - & - & - & - & - & - & - \\
\hline CSPH3 & - & - & - & - & 1.33 & 0.30 & - & - & - & - & - & - & - & - & - & - & - & - & - & - & - \\
\hline CSPH4 & - & - & - & - & 1.75 & 0.41 & - & 1.40 & - & - & 0.87 & - & - & - & - & - & - & - & - & - & - \\
\hline CSPH5 & - & - & - & - & 0.97 & 0.23 & - & - & - & - & 3.29 & - & - & - & - & - & - & - & - & - & - \\
\hline CVAL1 & - & - & - & 0.58 & 4.85 & - & 1.47 & - & - & - & - & - & - & - & - & - & - & - & - & - & - \\
\hline CVAL2 & - & - & - & 0.31 & 4.02 & - & 1.09 & - & - & - & 8.47 & - & - & - & - & - & - & - & - & - & - \\
\hline CVAL3 & - & - & - & 0.87 & 8.82 & - & 1.94 & - & - & - & 0.74 & 0.67 & - & - & - & - & - & - & - & - & - \\
\hline CFLV1 & - & - & - & 0.33 & 2.03 & 0.34 & - & 2.21 & - & - & - & - & - & - & - & - & - & 0.33 & - & 1.82 & - \\
\hline CFLV2 & - & - & - & 0.37 & 3.16 & 0.27 & - & 2.89 & - & - & - & - & - & - & - & - & - & 0.54 & - & - & - \\
\hline CFLV3 & - & - & - & 0.85 & 8.24 & - & - & - & - & - & - & - & - & - & 0.72 & 2.20 & - & 0.57 & - & - & - \\
\hline CPSE1 & 0.42 & - & - & 1.61 & 3.09 & 0.32 & 2.31 & - & - & - & 21.02 & - & - & - & - & - & - & - & - & - & - \\
\hline CPSE2 & - & - & 0.45 & 1.43 & 2.87 & 0.20 & - & 1.20 & - & 21.35 & 33.68 & - & - & - & - & - & - & - & 0.93 & - & - \\
\hline CRAM1 & - & - & 2.06 & 2.77 & 9.45 & - & - & - & 0.39 & 5.54 & 30.30 & - & - & - & - & - & - & - & - & - & - \\
\hline CJAP1 & - & 2.42 & 1.20 & - & 1.41 & 1.95 & 0.61 & 8.38 & - & - & 2.13 & - & - & - & - & - & 2.42 & - & - & - & - \\
\hline CJAP2 & - & 1.39 & - & - & 2.40 & 0.78 & 0.81 & 3.05 & - & - & 4.56 & - & - & 0.19 & - & - & - & 5.68 & - & - & - \\
\hline CFLG1 & - & - & 0.51 & 1.27 & 3.70 & 0.86 & - & 4.79 & - & - & - & - & - & 0.19 & - & - & - & - & - & - & 0.63 \\
\hline CFLG2 & - & - & 0.54 & 1.51 & 1.98 & 0.34 & - & 1.96 & - & - & 24.85 & - & 0.43 & - & - & 2.11 & - & - & - & - & - \\
\hline
\end{tabular}


Table 3. Continued

\begin{tabular}{|c|c|c|c|c|c|c|c|c|c|c|c|c|c|c|c|c|c|}
\hline \multirow{2}{*}{ Taxa } & \multicolumn{15}{|c|}{ Compound } & \multirow{2}{*}{$\begin{array}{c}\text { Total } \\
(\%)\end{array}$} & \multirow{2}{*}{$\begin{array}{c}\text { Compound } \\
\text { no. }\end{array}$} \\
\hline & 43 & 44 & 45 & 46 & 47 & 48 & 49 & 50 & 51 & 52 & 53 & 54 & 55 & 56 & 57 & & \\
\hline CSPH1 & - & - & - & - & - & - & - & - & - & - & - & 13.06 & - & 5.68 & - & 39.24 & 14 \\
\hline CSPH2 & - & - & 7.28 & - & - & - & - & - & - & - & - & 21.93 & - & - & - & 51.24 & 13 \\
\hline CSPH3 & - & - & - & - & - & - & - & - & - & - & 11.51 & - & - & - & - & 19.20 & 6 \\
\hline CSPH4 & - & - & - & - & - & - & - & - & - & - & - & - & - & - & - & 21.13 & 9 \\
\hline CSPH5 & - & - & - & - & - & - & - & - & - & - & - & 4.86 & - & - & 1.42 & 16.80 & 9 \\
\hline CVAL1 & - & 1.87 & 1.37 & - & - & - & - & - & - & - & - & 9.02 & 3.68 & - & - & 49.26 & 10 \\
\hline CVAL2 & - & 3.03 & - & - & - & - & - & - & - & - & - & 6.63 & - & - & - & 43.08 & 10 \\
\hline CVAL3 & - & 3.51 & - & - & - & - & - & - & - & 9.43 & - & - & 3.44 & - & - & 39.93 & 12 \\
\hline CFLV1 & - & - & - & - & - & - & - & 1.57 & 3.26 & - & - & - & - & - & - & 26.47 & 13 \\
\hline CFLV2 & 2.43 & - & - & - & - & - & - & - & 5.26 & - & - & - & - & - & - & 31.76 & 12 \\
\hline CFLV3 & - & - & - & - & - & - & - & - & - & - & 9.01 & - & - & - & - & 45.58 & 11 \\
\hline CPSE1 & - & 2.70 & - & - & 1.17 & - & - & 1.85 & - & - & - & 12.76 & - & 5.81 & - & 67.03 & 17 \\
\hline CPSE2 & - & 0.36 & - & - & - & - & - & 1.11 & - & - & - & 4.20 & - & 0.88 & - & 74.13 & 18 \\
\hline CRAM1 & - & 0.70 & - & 2.55 & - & - & - & 2.41 & 6.95 & - & - & - & - & - & - & 69.77 & 14 \\
\hline CJAP1 & - & - & - & - & - & - & 2.73 & 7.21 & - & 6.51 & - & - & 2.70 & - & - & 45.88 & 16 \\
\hline CJAP2 & - & - & - & 2.57 & - & 1.86 & - & 3.16 & - & - & - & 7.03 & 0.80 & - & - & 41.85 & 20 \\
\hline CFLG1 & - & - & - & - & - & - & - & 4.51 & 4.80 & - & - & 11.84 & 1.31 & - & - & 42.38 & 16 \\
\hline CFLG2 & - & - & - & 2.68 & - & - & - & 3.50 & - & - & - & 10.60 & 3.29 & - & - & 58.67 & 18 \\
\hline
\end{tabular}

Flagellifera were recombined to Group 1. C. japonicum and C. flagelliferum with altermate leaves can be classified according to the presence and absence of rossetted leaves and the number of bracteal leaves (Kim, 2007). The recent molecular phylogenetic study (Han et al. 2011) supported that $C$. japonicum and C. flagelliferum are allied species because of their close relationship.

Group 2 with opposite leaves was redivided into two subgroups. One subgroup comprised C. psuedofauriei in Ser. Sinica and C. ramosum in Ser. Oppositifolia. The number of common components in C. psuedofauriei, $C$. ramosum was 11 and similarity was found in chemical composition. But, compound 1, 6, 13, 22, 27, 28, 29, 40, 47, 54, 56 found in $C$. psuedofauriei weren't found in C. ramosum and compound 30, 46, 51 found in C. ramosum weren't found in C. psuedofauriei. These two taxa have a same important characteristic such as oppsite leaves, but have definite differences in features (spreading or erect) and colors of sepals, features of carpels (spreading or erect) and shapes of capsules. According to the recent boundary diagram using ITS analysis by Han et al.
(2011), C. psuedofauriei was firstly branched from outgroup (bootstrap, 98\%), and then C. ramosum formed close relationship with Ser. Pilosa (bootstrap, 95\%). The study of Han et al. (2011) showed somewhat different results from this study. So, it was estimated that additional close studies should be needed to determine the accurate systematic relationships. The other subgroup gradationally comprised $C$. flaviflorum, $C$. valdepilosum, C. sphaerospermum in Ser. Pilosa. Type of leaf, flower, fruit, seed and frequency of hair were key characters in the morphological taxonomy in Ser. Pilosa (Hara, 1957; Chung and Kim, 1988). According to features of seed surface ridges, C. flaviflorum didn't have ridges, $C$. valdepilosum had them slightly and C. sphaerospermum had them definitely (Han et al., 2010). According to the colors of bracteal leaves, C. valdepilosum was bright yellow, C. sphaerospermum was greenish or greenish yellow (Kim, 2007). Han et al. (2010) reported that $C$. flaviflorum was definitely identified from other taxa in that it had subhypogaeus stolon. According to the phylogenetic study using nrDNA of ITS sequence (Han et al., 2011), taxa of Ser. Pilosa formed close relationships. 


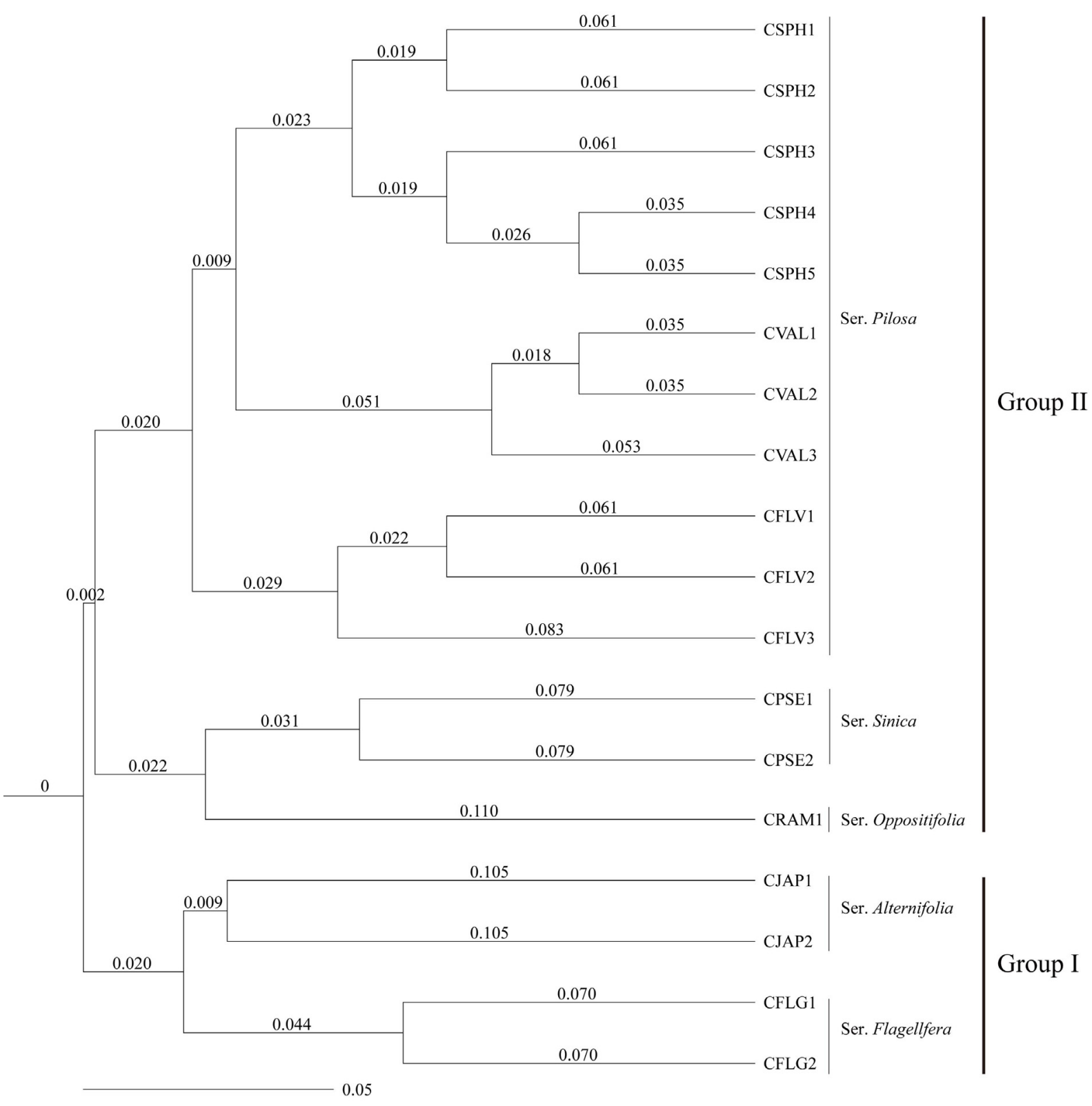

Fig. 1. UPGMA tree of the genus Chrysosplenium.

According to the results of this study, Ser. Pilosa was divided into 3 taxa; compound 3, 13, 14, 20, 26 were found commonly, but compound $5,10,19,36,41,43$ were restricted to $C$. flaviflorum, compound 33 was restricted to C. valdepilosum and compound $8,12,15,18,21,57$ were restricted to $C$. sphaerospermum. So, these findings could be an evidence to support those of existing morphological and molecular studies.

The results of this study were generally agreed to taxonomy according to morphological characteristics and systematics using nrDNA of ITS sequence. In conclusion, chemical composition using GC-MS analysis of 7 species and 18 populations of Chrysosplenium in Korea can be useful characters in understanding the relationship among interspecific and intraspecific complex. More comprehensive taxonomic studies introducing various chemotypes should be conducted and, consequently, these studies can make it possible to identify Chrysosplenium more accurately. 


\section{Acknowledgement}

This paper was supported by the Semyung University Research Grant of 2012.

\section{Literature Cited}

Bohm, B.A. and F.W. Collins. 1979. Flavonoid of some species of Chrysosplenium. Biochem. Syst. Ecol. 7:195-201.

Chung, T.H. 1965. Illustrated Encyclopedia of Fauna \& Flora of Korea. Tracheophyta. Genus Chrysosplenium. Ministry of Education, Seoul, Korea. 5:497-483.

Chung, T.H., B.S. To, D.B. Lee and H.J. Lee. 1937. Genus Chrysosplenium. In Nomina Plantarum Koreanum. Chosen Nat. Hist. Inst., Seoul, Korea. pp. 80-81.

Chung, Y.H. and Y.D. Kim, 1988. Monographic Study of Endemic Plants in Korea X. Taxonomy and Interspecific Relationship of the Genus Chrysosplenium. Korean J. Environ. Biol. 6(2):33-63.

Cudej, J. and P. Czapski. 2009. Components of the petroleum ether and chloroform extracts of Chrysosplenium alternifolium. Chem. Nat. Comp. 45(5):717-719.

Forbes, F.B. and W.B. Hemsley. 1887. An enumeration of all the plants known from China proper, Formosa, Heinan, Corea, the Luchu Archipelago and Island of Hong Kong. J. Linn. Sco. Bot. 23:271.

Franchet, A.R. 1890. Monographie du genere Chrysosplenium Tournfort. Nouv. Arch. Mus. Hist. Nat. Paris III. 2:87-114. Han, J.W., S.G. Yang, H.J. Kim, C.G. Jang and S.H. Kang. 2010. Morphological chaeacteristics and distribution of Korean endemic Chrysosplenium flaviflorum Ohwi. Korean J. Plant Res. 23(5):480-485 (in Korean).

Han, J.W., S.G. Yang, H.J. Kim, C.G. Jang, J.M. Park and S.H. Kang. 2011. Phylogenetic study of Korean Chrysosplenium based on nrDNA ITS sequences. Korean J. Plant Res.
24(4):358-369 (in Korean).

Hara, H. 1957. Synopsis of Genus Chrysosplenium L. Jour. Fac. Sci. Univ. Tokyo, Bot. 7:1-90.

Iwatsuki, K., D. Boufford, H. Ohba. 2001. Chrysosplenium L. In Flora of Japan, Vol. II b. Kodansha LTD., Tokyo, Japan. pp. 58-70.

Kim, Y.D. 2007. Saxifragaceae. In Flora of Korea Editorial Committee (eds.), The Genera of Vascular Plants of Korea, Academy Publishing Co., Seoul, Korea.

Lee, T.B. 1976. Vascular plants and their uses in Korea. Bull. Kwanak Arb. 1:1-137.

Lee, W.T. 1996a. Standard Illustration of Korean Plants. Academy Press, Seoul, Korea.

Lee, Y.N. 1996b. Flora of Korea. Kyohak Publishing Co, Seoul, Korea.

Linneus, C. 1753. Species Plantarum. p. 398.

Maximowicz, C.J. 1877 Diagnosis Plantarum Novarum Asiaticarum Scripsit. Bull. Acad. Sci. St. Petersb. 23:340-350.

Nakai, T. 1909. Flora Koreana. J. Coll. Sci. Univ. Tokyo, Japan. 26:220.

Palibin, J. 1898. Conspectus florae Koreae. Pars Prima. Acta. Horti. Petropol. p. 90.

Pan, J. 2001. Chrysosplenium L. In Wu, Z.Y. and P.H. Raven (eds.), Flora of China, Science Press and Missouri Botanical Garden Press, Beijing and St. Louis. 8:346-358.

Park, M.K. 1949. Genus Chrysosplenium. In An enumeration of Korean plants. Ministry of Education, Seoul, Korea. pp. 83-85.

Park, M.K. 1974. Genus Chrysosplenium. In Keys to the Herbaceous plants in Korea (Dicotyledoneae). Chungeumsa, Seoul, Korea. pp. 208-210.

Sponberg, G.L. 1972. The genera of Saxifragaceae in the South- eastern United States. Jour. Arnold Arb. 53:409-494.

Yang, Y.S., G.F. Shi, R.H. LU. 2004. Study on the volatile constituents of Tibetan medicine Chrysosplenium nudicaule. Chin. NPRD. 16:38-40. 